\title{
Repensar los clásicos
}

Dos libros han traído, con muy breve intervalo, noticia del "modus philosophandi" de Emilio Lledó ${ }^{1}$. Más allá del objeto respectivo de estudio, que reseñaremos a continuación, destaca siempre una concepción de la filosofía entreverada con — que no reducida a - los intereses recurrentes de los hombres de toda época. En una onda bien distinta de la llamada filosofía mundana, los escritos de Lledó provocan a menudo una sensación de lo inconcluso, como si las páginas se hubieran agotado antes de que se formulara la tesis definitiva o la respuesta final a las cuestiones planteadas. Esta suerte de ansiedad que tantas veces, por cierto, ha experimentado el lector de Platón, es la que permite ensayar una caracterización del estilo: filosofía de la pregunta.

De ningún modo queremos significar con esto que se desinterese de las propuestas de solución que, a los diferentes interrogantes, han ido produciéndose históricamente. Por el contrario, son objetos permanentes de investigación las claves semánticas y pragmáticas de toda tentativa de explicación, de todo ensayo de superación de alguna dificultad filosófica: "entender un texto será hacer que todos los sintagmas que lo configuran sean iluminados por todos los paradigmas ausentes que lo constituyen", bien sean éstos propiamente filosóficos o culturales ${ }^{2}$. Pero esta inquietud hermenéutica no acabaría de retratar la sencilla originalidad, reiterativa en sus principales presupuestos, que encierra el pensamiento de E. Lledó: su afán, resistente ante el conformismo que pudieran producir no importa qué tesis, se centra en indagar los porqués, en someter a rigurosa disección los planteamientos diversos

1. (I.) E. LLEDÓ, El epicureísmo. Una sabiduría del cuerpo, del gozo y de la amistad. Montesinos, Barcelona 1984. 1984.

(II.) E. LLEDÓ, La memoria del Logos. Estudios sobre el diálogo platónico. Taurus, Madrid

2. E. Lledó, 1984-II, p. 44. 
que pretenden resolver imperecederos problemas, en interrogar a los interrogantes mismos.

En efecto, los dos libros que comentamos tienen este rasgo coincidente. Para centrar las diferencias y aun disparidades que existen entre Platón y Epicuro, se trata de determinar el cómo y porqué, siendo así que les resultan comunes las grandes preocupaciones - vida, conocimiento, organización de la sociedad, relaciones humanas, ética, justicia... - se articulan las preguntas de manera tan específica en cada uno, con el alcance que eso tiene cuando se sabe que la respuesta está prefigurada en la pregunta. Lledó reivindica el carácter radicalmente moderno de la filosofía entendida como diálogo, y declara a la pregunta, ineludiblemente hecha desde el lenguaje, como "constitutivo esencial de la dialéctica" 3 . Por encima, pues, de lo que se dice saber, importa lo que se quiere conocer.

Junto a esta característica metodológica común, que es primordial, se percibe cierta divergencia de intención entre las dos obras. Si en la que se ocupa de Platón hay un análisis pormenorizado y detenido de ciertos aspectos monográficos, en la dedicada a Epicuro se adopta un tono distinto, dando lugar a una reflexión más abierta y a un intento de eliminar algunas tinieblas de nuestro tiempo mediante la luz hallada por el epicureísmo. Bien que las habituales distinciones entre libros especializados y divulgadores esconden a menudo maniqueísmos ideologizados que no podemos compartir, puede sostenerse que el libro sobre Platón se encuadra entre los primeros, como dirigido especialmente a un público interesado por la Filosofía, en tanto que la exposición de la filosofía epicúrea se vuelve hacia todo tipo de lector con tal que no esté desentendido de la realidad en que vive.

\section{El epicureísmo y la vida}

Una vez reconocida la reciente recuperación del pensamiento epicúreo - con valiosas ediciones, entre nosotros, de su obra ${ }^{4}$ - nuestro autor evita una nueva exposición sistemática. Por ello, se propone un rescate activo del poder vivificador e inquietante de su doctrina. La epicúrea fue una filosofía fundamentalmente orientada a la práctica, interesada en pensar las condiciones de la vida humana inmediata, y esa es precisamente la que se nos señala como máxima originalidad: haber construido un pensamiento que, intentan-

3. E. LLEdó, 1984-II, p. 201.

4. Anotemos, en especial, dos: la de García Gual y Acosta Méndez, Epicuro. Ética. Barral, Barcelona 1974; y la de GARCía CALvo, Lucrecio. De la naturaleza de las cosas. Cátedra, Madrid 1984. 
do una investigación racional de la realidad que ha de vivirse, no ha perdido en ningún momento este horizonte. La problemática no era muy distinta, cierto es, de la platónica o la aristotélica, pero resulta innegable que la lectura de los fluidos diálogos de Platón o de los compactos escritos de Aristóteles exige a menudo una explanación, un desentrañamiento de sus complejas especulaciones. Por el contrario, Epicuro, siquiera en los restos fragmentarios que de su producción han pervivido, sorprende al lector con la diafanidad de sus propuestas.

Interpretar las palabras de Epicuro no plantea excesivas dificultades, sobre todo si se tienen en cuenta las particulares condiciones histórico-políticas que han envuelto su emisión: desvirtuado el modelo de sociedad que había constituido la "polis" griega, parecen perder su sentido las grandes aspiraciones de edificar una sociedad que sea al tiempo solidaria y organizada. El epicureísmo se dirige a los individuos de este momento.

Pero es aquí necesaria una llamada de atención sobre las enfrentadas consecuencias que, de esto último, pueden extraer diversas lecturas. La visión más extendida, que, por cierto, se ha teñido contra el epicureísmo de un encono raramente conocido ante una tendencia filosófica, ve en el pensamiento epicúreo (fácilmente convertible en cliché por su referida fragmentación) algo negador: de principios morales, de costumbres, de ideales sociales de justicia, etc. Lledó, en cambio, nos sugiere otra clave para entender ese pensamiento; como en otros duros momentos de la historia, se extienden las supersticiones, las envolturas ideológicas, para transmitir a los hombres la necesidad de aceptar sus condiciones de penuria, sometimiento, o dolor. Contra esto, la función de la doctrina epicúrea habría sido así, ante la embrutecedora tarea realizada por la imperante religión astral de su tiempo, básicamente afirmadora.

Puede sostenerse este carácter positivo de la filosofía epicúrea si se considera su coherente desarrollo. Su teoría del conocimiento vincula toda noticia del mundo externo a la sensación, y la sensación es un proceso de naturaleza corpórea; así, pues, como la muerte consiste en la desaparición corporal, y ninguna sensación puede perturbarse tras ella, es obligado abanderar una vida para la vida, un ser en función del cuerpo. El epicureísmo proclama la necesidad del placer como fenómeno ligado a las sensaciones corporales, lo que es decir como raíz positiva del vivir humano.

Epicuro, a quien Lledó llama "filósofo del orden terrestre", rompe con las tradicionales dicotomías filosóficas: alma-cuerpo, ciencia-pseudosaber, ideas-sensaciones... No puede decirse que prime la atención al cuerpo sobre la debida al alma - pues de ahí emanan todas las conocidas distorsiones de su pensamiento-, sino que se afirma la unicidad del cuerpo. Ha de atender- 
se al cuerpo, ha de intentarse su vivencia apacible, porque no hay otra cosa: en este posicionamiento monista se funda su frontal ataque contra las actitudes farisaicas, contra la moral de doble cara (que distingue entre lo que se recomienda a los demás y lo que uno mismo practica).

No podríamos terminar nuestro comentario sin señalar que, a nuestro personal entender, lo más lúcido y fecundo de este librito sobre el epicureísmo se halla en los análisis que, desde los textos originales de la filosofía del Jardín, hace Lledó de manifestaciones generales de nuestro tiempo. Tan importante como restaurar el valor que la obra de Epicuro y sus seguidores tuvo en su época es, aquí, mostrar la vigencia que pueden hoy acreditar su rigor intelectual y su atemperado hedonismo; especialmente cuando se reflexiona sobre la banalidad de los detentadores del poder, sobre el consumismo desenfrenado, en torno a la insolidaridad y a las flagrantes desigualdades en nuestra convivencia, o acerca de la proliferación de los fanatismos. Porque muchas de sus máximas morales parecen formuladas pensando en nuestra cotidianidad presente es por lo que deben leerse con aprovechamiento no meramente teórico.

\section{La filosofía dialogada}

Este nuevo libro sobre la obra de Platón no es exactamente una obra nueva. Se recogen en el volumen varios ensayos —uno de los cuales, "La memoria del Logos" da título al conjunto — publicados en distintos medios a lo largo de los últimos veinticinco años. Los lectores familiarizados con la bibliografía platónica encontrarán que casi la tercera parte de este volumen reproduce la Introducción general que el autor escribió para los Diálogos ${ }^{5}$. Resulta revelador, del tono permanentemente abierto con que Lledó se enfrenta a los nombres y a los textos de la historia de la filosofía, que la presentación fragmentada y con nueva estructura de esa Introducción no distorsione en absoluto su seguimiento. Hay una sólida coherencia en el modo de leer filosofía, por encima de las presentaciones académicas de la misma.

No nos detendremos en el análisis de esos trabajos introductorios a la literatura platónica, aunque sí señalaremos la enorme importancia que el autor confiere a lo que podríamos llamar el estilo del filosofar de Platón, el diálogo. Muy a pesar de algunas críticas atribuciones de totalitarismo a Platón, toda filosofía posterior deberá referirse inexcusablemente a la dialéctica

5. La editorial Gredos inició la publicación de los "Diálogos de Platón en 1981. Hasta el momento han aparecido varios de los que contempla ese proyecto de su Biblioteca Clásica. 
como marco ofrecido a la indagación no dogmática, al contraste de pareceres, a la puesta en común. Este personaje tan frecuentemente tratado con calificaciones y descalificaciones estereotipadas que fue Platón, resulta paradójicamente ser el filósofo de la continua remodelación de las tesis, de la apertura a nuevos matices que pueda introducir en el diálogo cualquiera de sus interlocutores, del "pensamiento compartido", en suma ${ }^{6}$. La oposición de tesis, los problemas irresueltos, la habitual ausencia de final feliz en sus escritos, pueden merecer los más opuestos juicios; no obstante, continuarán siendo el reflejo de las verdaderas esencias del filosofar, en tanto que recurrente interrogarse.

Vamos a considerar los dos ensayos más relevantes, al margen de los ya referidos, de entre los que integran esta edición: "El prisionero de la caverna" y "La memoria del Logos".

El primero de ellos constituye un espléndido ejercicio práctico de comentario de textos filosóficos, en el que se intercalan algunas consideraciones de carácter teórico sobre cómo ha de abordarse esa tarea comentadora. Se recurre, para ello, a uno de los pasajes más conocidos de la literatura filosófica: el mito de la caverna narrado en los comienzos del libro VII de la "República". Tal ejercicio se emprende desde la previa convicción de que, como todos los fenómenos de creación artística, la narración mítica no es un producto clausurado sino que, muy al contrario, su grandeza reside en la capacidad de evocación y sugerencia de pensamientos y sentimientos que poseen. Esa convicción es la que impulsa a rastrear nuevos significados, renovadas interpretaciones.

Semejante indagación rebasa, incluso, la literalidad de los propósitos del mismo autor del texto, del verdadero creador del mito. Aunque Platón, en este caso haya establecido un corolario para sus propias palabras y para el especial cuadro que éstas pịtan, es posible - aún más, es deseable-intentar extraer conclusiones otras. Los muchos siglos que este mito lleva dejando oír su eco han terminado por consagrar una a modo de versión oficial de su contenido. Pero Lledó nos invita a remover todos los conceptos que en él se incluyen, y hasta a realizar el imaginativo juego de introducir, en la escena, personajes innombrados por Platón, pero que muy bien podría haber formado parte de la situación. El filósofo puede apropiarse del texto mítico.

Naturalmente, no todas las apropiaciones que se hagan resultarán idénticas, ni deben tampoco catalogarse como coherentes por el mero hecho de haberse efectuado. Por ello, Lledó nos presenta una interesante sucesión de lecturas posibles del mito de la caverna, eludiendo optar por una sola en

\footnotetext{
6. E. LLEDÓ, 1984-1I, pP. 35ss.
} 
detrimento de las demás. Así, una lectura antropológica permitiría representarse la condición humana en el desempeño de papeles distintos: los encadenados - a su propia cultura y lenguaje - que están siendo engañados, y los ejecutores del engaño, que son quienes transportan sobre sus cabezas las figuras cuya sombra se proyectará en el fondo e, incluso, los no mencionados pero posibles personajes que, entre bastidores, habrían ideado la situación y moverían los hilos que la mantienen.

Lecturas epistemológicas son las que más frecuentemente se han hecho del mito. Indudablemente, la caverna es un recinto en el que se vive la falsedad; pero el conocimiento superior no viene caracterizado por una simple huida al exterior del antro, sino por una revisión crítica de lo que allí hay - sombras contempladas y voces oídas - en dos niveles: el fuego como discurso racional, el sol como episteme.

Otras lecturas pueden ser hechas. Desde una social, en la que los honores que se disputan los prisioneros pueden interpretarse como similares a los privilegios que el juego de los políticos concede a quienes se pliegan a la fuerza de sus intereses, hasta una psicoanalítica. Desde una lectura trágica, desesperando de poder modificar las condiciones de nuestra existencia, hasta una "televisiva" - sugerente propuesta - en la que el prisionero de la caverna encarnaría el papel del hombre contemporáneo, pasivamente sentado ante la televisión que, con los demás medios de comunicación de masas, uniforma y perfila a su antojo unos contenidos informativos sustitutorios de su capacidad de pensar y juzgar por sí mismo.

Lo que llama la atención a Lledó es que este singular mito nunca se haya leído en clave ética, dado que la Idea de Bien está dada, en el sol, como referencia máxima. Cuando a propósito de la caverna se trata del conocimiento, se olvida a menudo que la de éste es una función liberadora, colectivamente liberadora, pues no basta con que uno pueda conocer (salir afuera) sino que ha de retornar en pos del rescate de quienes aún quedan dentro. Lejos de proyectos irrealizables como la consecución de una libertad absoluta, que desde el estoicismo sabemos inexistente, ha de perseguirse la liberación. Y ésta no puede activarse sino mediante la educación: más que sacar a los hombres de la caverna hacia la luz, hay que llevar la luz al interior de aquélla. Acaso la mejor forma de hacer la luz entre nosotros sea releer las palabras de los filósofos, cuyo desoimiento ha provocado el más cavernario signo de nuestros tiempos: el empobrecimiento de los espíritus, "la galopante deflación de los cerebros". 7 .

7. El Lledó, 1984, p. 33. 
"La memoria del Logos" es la feliz expresión que resume el análisis del diálogo "Menón", a la par que encabeza el ensayo dedicado al problema de la "anámnesis" en Platón. Del mismo modo que al reflexionar sobre el mito de la caverna, el autor se despega aquí de todos los convencionalismos interpretativos, de todos los esquemas que, con el tiempo, han ido normalizándose hasta terminar recubriendo los matices originales como una costra que los oculta y desfigura.

Para entender la teoría platónica del conocimiento como "anámnesis" -recuerdo, reconocimiento, recuperación- es uso remitirse a las influencias órfico-pitagóricas que, al menos en la cuestión de la pre-existencia del alma y sus experiencias anteriores, Platón recibió. Pero ello encierra el peligro de que, si se rechaza la transmigración, la teoría se derrumbe totalmente.

Cabe, sin embargo, realizar otra aproximación al problema desde el propio texto platónico. El tratamiento de la "anámnesis" encuentra su más conocida expresión en el diálogo que Sócrates mantiene con un esclavo de Menón, guiado por la intención de mostrar que es posible a un hombre, como él no-instruido, acceder por sí mismo a conocimientos de geometría. Esa posibilidad se despliega en las alternancias características del diálogo, en la continuada indagación que el intercambio dialéctico contiene.

Para iniciar su tarea mayéutica, Sócrates no inquiere más que un dato sobre el esclavo que va a ser su interlocutor, prescindiendo de todos los rasgos sociales, políticos, intelectuales, etc.: es preciso conocer si tienen en común la lengua hablada. Esta aparente banalidad - pues, en efecto, es imposible la intelección entre dos personas con distinto idioma - vertebra la reinterpretación que aquí se hace de la sabiduría latente en el esclavo: posee un lenguaje o, por mejor decir, su entendimiento se ha forjado con un lenguaje como material constructivo principalísimo. El único requisito socrático ${ }^{8}$ que se impone al esclavo se convierte en punto crucial de la teoría del conocimiento de "Menón"; el lenguaje (el griego en este caso), en tanto que depositario ancestral de la sabiduría del pueblo que lo habla, la guarda como precioso recuerdo. Ésa es la "memoria del Logos": lo que las palabras han ido atesorando con el paso del tiempo.

De este modo, la "anámnesis" deja de ser una consecuencia de la búsqueda dialéctica para, muy al contrario, convertirse ella misma en condición de posibilidad del diálogo. Sólo es posible la persecución incesante del conocer si se da la posesión del logos que recuerda, del lenguaje que es él mismo pre-conocimiento.

8. ¿Es griego y habla griego?" pregunta Sócrates a Menón, p. 136. 
No creemos preciso encarecer más, tras los comentarios precedentes. lat fecundidad de estas relecturas de Epicuro y Platón. Cabría, únicamente, objetar cierta indefinición de las figuras de Platón y de los sofistas respecto del epicureísmo, pues puede darse la impresión de que se dulcifican los aspectos reactivos de esta doctrina frente a lo que Platón y la Academia habían representado en lo político y en lo filosófico.

Juan Á. CANAL.

Licenciado en Filosofía

Valladolid 